\title{
Analysis of Chinese Welding Industries Today and in the Future (Focus on Cost, Productivity, and Quality)
}

\author{
Xiaochen Yang, Paul Kah, Jukka Martikainen \\ Laboratory of Welding Technology, Lappeenranta University of Technology, Lappeenranta, Finland
}

Email address:

xiaochen.yang@lut.fi (Xiaochen Yang),paul.kah@lut.fi (P. Kah), jukka.martikainen@lut.fi (J. Martikainen)

To cite this article:

Xiaochen Yang, Paul Kah, Jukka Martikainen. Analysis of Chinese Welding Industries Today and in the Future (Focus on Cost, Productivity, and Quality). International Journal of Mechanical Engineering and Applications. Vol. 3, No. 6, 2015, pp. 127-133.

doi: 10.11648/j.ijmea.20150306.15

\begin{abstract}
This paper make a detailed survey and research about the real situation about Chinese welding industry, and the future cooperation suggestion between Finland and China in this area. This topic was approached by searching for the latest and most accurate information through interviews, site visits, websites, books and promotional materials. The site visits are the most important. The destination cities in China cover a large range from northern to the southwestern areas in China. More than 15 professional welding factories or factories which have a welding workshop were visited, and based on discussions and an investigation in those factories; detailed and reliable data was collected. By using and analyzing that information, a general profile of modern Chinese welding factories was generated.
\end{abstract}

Keywords: Welding Quality, Finland-China Co-operation, Welding Cost, Welding Productivity, Welding, TWM

\section{Introduction}

Finnish and European welding factories are currently finding it difficult to hire professional or expert welders because the lack of labor force. Many companies choose to buy welding products from China, and therefore, more and more Chinese welding factories become subcontractors to Finnish contractors. As a result of this trend, Finnish companies wish to obtain the latest and most accurate information of the status of the Chinese welding industry and factories in order to support their business decisions. The background of this paper is the HitNet-Global project of TEKES. One aim of this project is to understand the real situation of the Chinese welding industry exactly. The information about Chinese welding industry will be collected from Chinese welding institute, Chinese welding factories and some of the Chinese universities. The information includes the welding productivity, the welding cost, and the quality control situation in China.

After the survey period, many problems were found in the welding processes in Chinese welding factories. How to balance the low cost and unsatisfactory quality of Chinese products nowadays becomes the top significant issue does not only exist in the welding industry. A more better and reliable regulatory approach or a more proper qualification system of Chinese welding factories should be studied in future as quickly as possible $[12,15]$.

In conclusion, a mutual understanding of the culture, lifestyle and customs between the East and West also play an important role in future cooperation.

\section{Overview of Welding Industries in China}

The welding industry is one of the most important branches in the Chinese manufacturing industry. According to a report on the Beijing Essen Welding and Cutting Fair, the exhibitors' number has increased $12.36 \%$, while the professional visitors' number has increased by $45.82 \%$ and the exhibition space by $33.23 \%$ during 2009 and 2010 [1] [2]. The increasing trend indicates that more people were interested in the welding industry, and more foreign companies regard China as their significant partner in cooperation and their present and future market.

This study on the Chinese welding industry is divided into two areas: research on welding equipment and new welding technologies, and the application of welding methods. Research on the first subject area is carried out in professional institutes, universities, and large enterprises. The examination of the second subject area covers nearly all of 
the areas of China which is include steel structure manufacturing, ship building industry, construction machine fabrication, high pressure vessel assembly, and chemical metallurgical industry.

There are all types of welding processing workshops in China: small and medium-sized workshops, and large-scale welding factories. The private small and middle-sized workshops occupy a large market share in China. Many large factories are closing their welding workshop and moving their welding work to smaller companies, thus focusing only on their assembly plant. This kind of cooperation pattern is becoming the prevailing trend not only between foreign companies and Chinese subcontractors, but also between stateowned enterprises and small private factories within China.

In the field of international commercial cooperation, Finnish companies also perform a great deal of commercial activities in China, but choose different cooperation patterns. Some companies choose Chinese welding factories as their subcontractors, and the final assembly work of their product is finished in Finland. Others choose to build their own or joint venture factories in China in which all work from welding to machining and assembly is carried out. However, the targets of all of the Finnish companies are same: higher productivity, lower costs, and reliable quality.

A Finnish company $\mathrm{J}$, which is specialized in the design, manufacture, and service of hydraulic piling equipment, has chosen the first cooperation mode and cooperates with a specific Finnish agency called Ea (see Figure 1) [3].

The agency is in charge of the contact with Chinese industry, the quality control, machine part transport, and contracts with Chinese suppliers.

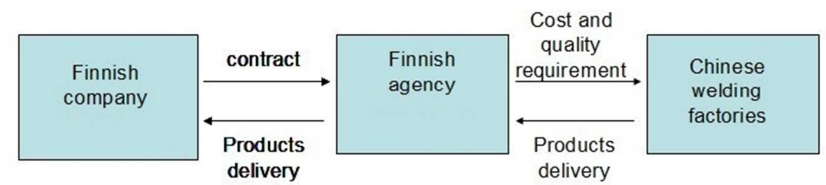

Fig. 1. The cooperation model between Finnish and Chinese welding industries.

The other collaboration model - building factories in China - requires Finnish companies to understand the Chinese welding industry more accurately and in detail. However, most of the small enterprises in Finland or Europe do not have much experience of collaboration with Chinese industry.

\section{Case Studies}

Three aspects of Chinese welding factories will be examined: the productivity, the economy and cost, and the quality control system. Productivity is determined based on the following factors: the number of workers (welders), the customers, workers' qualification, the plant situation, equipment and machines, auxiliary materials and gases, the environment and climate conditions, and other factors.
Economy and cost are analyzed based on the wages of staff (workers and management teams), the cost of materials (main material and auxiliary materials), the cost of processing, the cost of logistics, the margin and turnover, and other factors. Quality and quality control are determined by the processing methods, the welding procedure qualification record (WPQR) and welding procedure specification (WPS), human and cultural factors, the assessment and training of welders, inspection methods, the maintenance and repair of equipment, storage conditions, and environmental and climate conditions. The final objective is to find out the most suitable Chinese subcontractors.

In this section, all of the information above on six Chinese welding factories or workshops in different areas and industries will be listed. The information is based on the site visits by the author to each factory.

\subsection{Company $A$}

The main product of this factory is hydraulic support for coal mines. This factory is located in Beijing, North China [4].

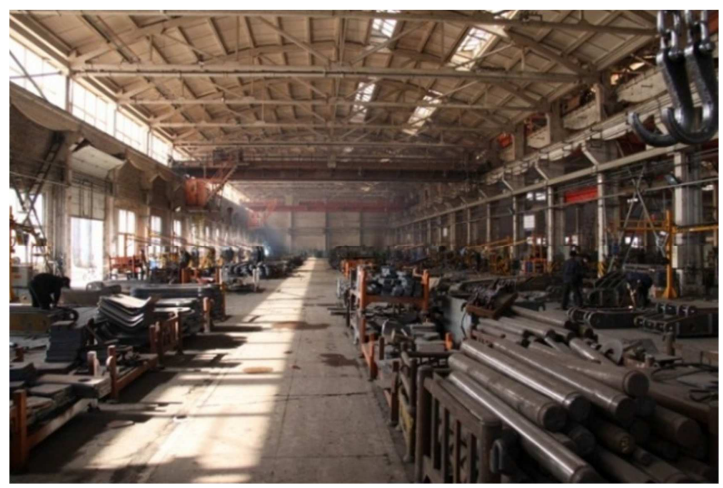

Fig. 2. Working environment of Company A welding factory (photo by author).

Number of workers: 6 welding workshops, almost 1000 welders.

Workers' qualifications: $1 / 4$ of the welders are senior technicians, and 3/4 of them are intermediate technicians. Every welder in this factory has a welding technician certificate.

Plants: Welding plant, machining workshop, and cutting workshop.

Manufacturing tools: CO2 MAG and MMA welding.

Materials: Main material: steel board, steel type: Q550, Q460, Q690 (based on GB221-79, the China national standards).

Welding wire: flux-cored welding wire: type 77, 78, 702; solid welding wires: JL-80M.

Environment: No special temperature and humidity control method.

Logistics costs: Highway and railway transportation, shipping.

Processing costs: Water, plant transport, propane gas, oxygen gas, and electricity.

Other costs: Equipment depreciation, warranty service, 
and rework cost for defective products.

Turnover: 3 billion RMB yuan in the year 2010 .

Processing steps: Raw material cutting $\rightarrow$ cold machining (some parts) $\rightarrow$ heat treatment $\rightarrow$ riveting and welding (spot welding and assembly) $\rightarrow$ aging process (some parts) $\rightarrow$ seam filling welding $\rightarrow$ cold machining (some parts) $\rightarrow$ assembly.

Cultural factors: Zhangjiakou city (Hebei province), Huludao city (Liaoning province), and Shijiazhuang city (Hebei province), North China.

Worker training: Security assessment and skill assessment.

Inspection methods: Personnel from the quality assurance office. The following aspects are inspected: appearance of the welding seam, size of the part, welding slag, gas stoma, oil pollution, and quality of the welding seam.

Machine maintenance: Everyday basic cleaning and weekly professional maintenance.

Material storage and treatment: Special warehouse and pretreatment in order to remove rust. The storage of steel board inside will reduces the corrosion.

Environment and climate: The dry and cold winter requires preheating of the materials. Warm method (heating system in the workshop) for welders.

\subsection{Company B}

The main business of this factory is machining for steel structures. This factory is located in Shijiazhuang city, North China [5].

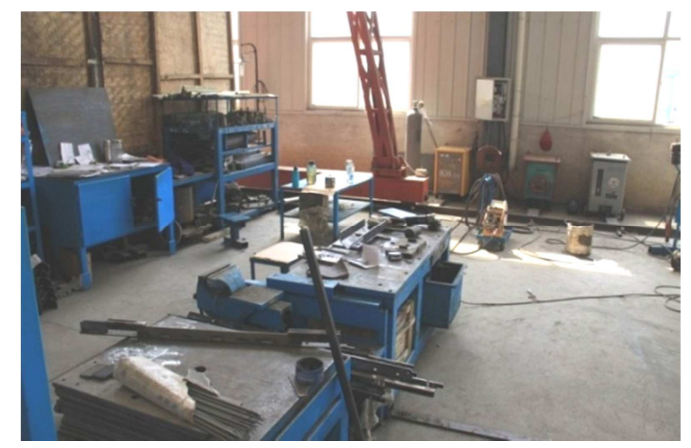

Fig. 3. Working environment of Company B (photo by author).

Number of workers: 50 workers, 10 of them are welders.

Workers' qualifications: Two of the welders are senior technicians, five are technicians. All other workers are senior technicians.

Plants: Two workshops; the total area for welding is 2650 $\mathrm{m} 2$. The courtyard area for storage and truck parking is 1200 $\mathrm{m} 2$.

Manufacturing tools: MIG (Argon as shielded inert gas) welding machine $\times 1$; MAG ( $\mathrm{CO} 2$ as shielded active gas) welding machine $\times 2$ (Chengdu Gaoxin KH-350); AC MMA welding machine $\times 5$ (Hebei welding machine factory $\mathrm{BX} 3$ 500J and BX1 500).

Materials: Stainless steel, aluminum, carbon steel, and copper.

Environment: All the welding works are certified by the
Chinese National Environment Performance Assessment. Noise, waste gas and water emissions all meet the standards. The temperature and humidity do not influence welding works in the North China area.

Workers'salary: 2500 to $3000 \mathrm{RMB}$ yuan per month. The workers' wages account for the $1 / 3$ of the total costs of the factory.

Materials costs: According to the market prices. The cost of materials is approximately $1 / 3$ of the total costs. The price of $5 \mathrm{~mm}$ thick steel board was approximately $5000 \mathrm{RMB}$ yuan per ton in the year 2011 .

Logistics costs: Logistics, processing and other costs are roughly $1 / 3$ of the total costs, and the logistics costs amount to approximately $10 \%$ of the total costs. Truck, labor and petrol costs, highway fees and management fee to the government.

Processing costs: Water (4 to 6 RMB yuan per ton, general industrial water price for the year 2011 in North China), argon, oxygen, acetylene, carbon dioxide, hydrogen, electricity (1 RMB yuan per KWh, general industrial electricity price for the year 2011 in North China) and all types of welding rods.

Other costs: Depreciation cost for manufacturing machines and cost of equipment loss. For taxes, the middle-sized welding and machining factories in North China have a $10 \%$ margin. The tax costs are approximately $17 \%$, but $12-13 \%$ will be paid by the customers. The taxes include $1 / 4$ of the profit, a channel environment charge, the income tax of workers, a disabled worker tax, and an environment management tax.

Turnover: 5 to 6 million RMB yuan per year.

Processing steps: Engineering drawing reading and review $\rightarrow$ processing design $\rightarrow$ manufacturing plan $\rightarrow$ materials preparation $\rightarrow$ processing steps (heating treatment) $\rightarrow$ manufacturing (machining and welding) $\rightarrow$ inspection (every processing steps) $\rightarrow$ packaging $\rightarrow$ products ready.

Cultural factors: Shijiazhuang city, Hebei province (North China).

Worker training: Training in safety and professional skills.

Inspection methods: The welding size, flatness of welding seams, and cracks are the inspected items. The full nondestructive test (NDT) is conducted only upon the customers' request.

Machine maintenance: Machine maintenance on Saturdays and major machine maintenance annually.

Material storage and treatment: Steel board and materials: indoor environment in the workshop. Welding wire and welding rods: special warehouse. The oxygen: isolated warehouse.

Environment and protection: Overalls, special masks, welding glasses, and welder gloves. Fan to control the temperature in the summer.

\subsection{Company $C$}

This is one of the largest and most professional manufacturers of steel-manufacturing equipment in North 
China. It is located in the city of Tangshan [6].

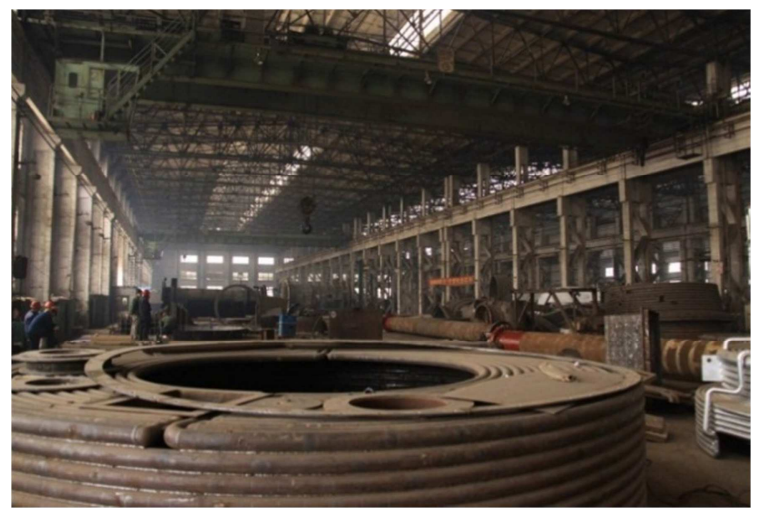

Fig. 4. Working environment of the Company C (photo by author).

Number of workers: Three welding plants, 20 senior welding technicians, 80 welders.

Workers' qualifications: Senior welding technicians with national boiler and pressure vessel welder certification.

Plants: 1.4 million mm2, of which $82000 \mathrm{~mm} 2$ consists of manufacturing workshops.

Manufacturing tools: MIG (argon as shielded inert gas) welding; MAG (CO2 as shielded active gas) welding machine (NBC-500 and NB7-500, Tangshan Greatwall welding machine factory); AC MMA welding machine; SAW machine $\times 1$.

Materials: K235, Q345, Cr-Mo steel, heat-resistant steel, low alloy steel.

Environment: Pre-heating works for thick steel boards in the winter.

Workers'salary: 1200 RMB yuan per month, including the five insurances and one fund. The technician welders' wage is $2000 \mathrm{RMB}$ yuan per month.

Materials costs: $60 \%-70 \%$ of the total costs.

Logistics costs: $10 \%$ of the total costs. $90 \%$ of the transportation methods are highway transport.

Processing costs: Welding wire, welding rod, carbon dioxide, argon, oxygen, diesel oil, water, and electricity. 5\% to $10 \%$ of the total costs.

Other costs: The worker's wage and depreciation cost for manufacturing machines and cost of equipment loss is $10 \%$ of the total costs. The margin is approximately $10 \%$, of which $23 \%$ is the sales tax. The value-added tax is $17 \%$.

Turnover: 0.21 billion RMB yuan for the year 2010. The average turnover for the past five years is 0.2 billion RMB yuan.

Processing steps: Material re-examination $\rightarrow$ material cutting (CNC flame cutting) $\rightarrow$ coiling and drilling $\rightarrow$ assembly (spot welding) $\rightarrow$ seam welding $\rightarrow$ NDT $\rightarrow$ heat treatment $\rightarrow$ painting $\rightarrow$ pressure testing (for boilers and containers) $\rightarrow$ products delivery.

Cultural factors: Tangshan or Qian'an city, Hebei province (North China).

Worker training: Safety training and certificate check.

Inspection methods: Material delivery period: ultrasonic, chemical component, tensile strength and yield strength tests. Welding seam: size checking, ultrasonic, radiation, magnetic particle, and penetration detection.

Machine maintenance: Everyday machine maintenance by the maintenance department.

Material storage and treatment: Steel board: outside storage area. Welding wire and welding rods: inside warehouse.

Worker protection: Mask, gloves, flame retardant overalls, and workers' boots.

\subsection{Company D}

Three individual factories: Company D1, Company D2, and Company D3. Xuzhou, Jiangsu, eastern and coastal areas, construction machinery industry [7].

Number of workers: D1: 400 workers; 200 of them are welders. D2: The labor productivity is $300000 \mathrm{RMB}$ yuan per one worker per one year. The industry net value added is currently $20 \%$.

Workers' qualifications: $95 \%$ of the workers are postsecondary technical school students, $70 \%$ of them are college students. In the key positions, $5 \%-10 \%$ of the workers are undergraduate students.

Plants: D1: The entire area of the factory is 2666 acres; the area of the steel structure workshop is 200 meters $\times 150$ meters.

Manufacturing tools: D1: MAG (CO2 as shielded active gas) welding, MAG inverter welding machine (PANASONIC), automation liner welding machine $\times 2$, welding robot $\times 1$.

D2: MAG (CO2 as shielded active gas) welding, MAG inverter welding machine (PANASONIC: KRII 500 or LINCOLN welding machine) $\times 20$. Welding wire: MAG WELDING CHW-50C6 (Shanghai Atlantic Welding Consumables Co., Ltd.). RE: Gas plasma cutting, contour cutting, MAG (CO2 as shielded active gas) welding, laser welding, and robotic welding.

Materials: D1: Steel board, steel type: 70 steel. RE: Steel board, steel type: medium carbon steel, and Q235.

Environment: The entire plant basement is covered with a whole sealed steel board in order to prevent the leakage of petroleum. Thermostat and humidity controlled plants.

Workers' salary: D2: the average wage is $60000 \mathrm{RMB}$ yuan per year (workers and middle managers). D1: the average wage is $4500-4700 \mathrm{RMB}$ yuan and $1500 \mathrm{RMB}$ yuan housing accumulation fund per month for welders.

Materials costs: $40 \%$ of the total costs, the gross profit margin of the mechanical industry are currently approximately $20 \%$.

Logistics costs: $1 \%$ of the total costs, road transport and railway transport.

Processing costs: Labor costs amount to $20 \%$ of the processing costs. The total processing costs are roughly $10 \%$ of the total costs.

Other costs: The selling expenses are $3 \%$ of the sales price. Office supplies, a shuttle bus for workers, business travel, hospitality, canteen costs, maintenance of other assets, 
R\&D expenses, testing costs, and rework cost; the percentage in the total costs is very small.

Turnover: D2: 2.2 billion RMB yuan last year. D1: 0.98 billion RMB yuan for 2009, 2 billion RMB yuan for 2010, and the prospective turnover for 2011 is 4.5 billion RMB yuan.

Processing steps: D1 and D3: incoming inspection (Chemical elements: carbon, manganese, silicon, sulfur and other alloying elements. Physical inspection: yield strength, tensile strength, and bending strength. Metallographic analysis: hardness) $\rightarrow$ raw material cutting $\rightarrow$ pretreatment (heat treatment) $\rightarrow$ cold machining (some parts) $\rightarrow$ heat treatment $\rightarrow$ riveting and welding (spot welding and assembly) $\rightarrow$ aging process (some parts) $\rightarrow$ seam filling welding $\rightarrow$ cold machining (some parts) $\rightarrow$ assembly. D2: incoming inspection (Chemical elements: carbon, manganese, silicon, sulfur and other alloying elements. Physical inspection: yield strength, tensile strength, and bending strength. Metallographic analysis: hardness) $\rightarrow$ pretreatment $\rightarrow$ cutting $\rightarrow$ riveting and welding $\rightarrow$ painting.

Culture factors: Xuzhou city or other cities in the Jiangsu province (eastern and coastal areas).

Worker training: The regular staff has classes and training every year, taught by experts from institutes, professors form universities, and engineers from other companies.

Inspection methods: Ultrasonic testing, magnetic particle testing, and turbine testing. The inspection is carried out by personnel (200-person team, 10 of them quality engineers) from the quality assurance office.

Machine maintenance: Everyday basic cleaning and maintenance, and monthly professional maintenance.

Material storage: Satisfaction for the national standard requirement.

Worker protection: Protected by special protective gear for welding work.

\subsection{Company $E$}

This is a producer of globally high-end offshore vessels, located in Ningbo city, Zhejiang, in the Eastern and coastal area [8].

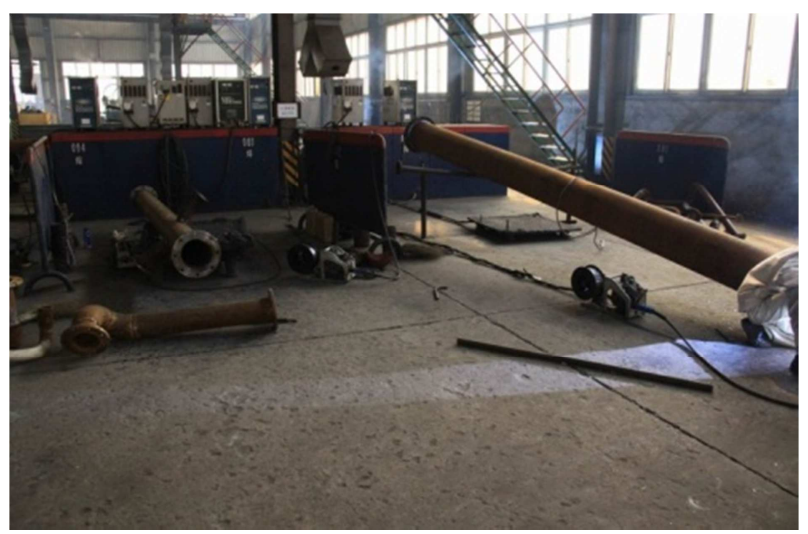

Fig. 5. Working environment of Company E (photo by author).
Number of workers: Two welding workshops, 1300-1400 welders from outsourcing labor force companies. 70-80 regular staff welders.

Workers' qualifications: 1000 welders are intermediate technicians. 300 are apprentice welders.

Plants: Welding workshops for ship body sections and small parts.

Manufacturing tools: Overall, $90 \%$ of the welding works were finished by MAG (CO2 as shielded active gas) welding using a MAG inverter welding machine (OTC: XD 500S; PANASONIC: KR II 350; Zhoushan Donghai electrical welder manufacturing co., ltd.: MR3151), and $10 \%$ of the welding works consist of submerged arc welding (Zhoushan Donghai electrical welder manufacturing co., ltd.: MZ-1250-2) and MMA welding (Zhoushan Donghai electrical welder manufacturing co. ltd.: ZXE 1-500). TIG welding and fillet welding are using for patches, repair, tube welding or fine welding.

Materials: Carbon steel board and stainless steel (according to the A to E levels). Welding wires: $3 \mathrm{Y}$ level welding wire, Antai QJ 501 and Jintai 712C.

Environment: If it rains, welding works is stopped. In strong wind, MAG welding is stopped.

Workers' salary: The intermediate technician wages are 3000 RMB yuan per month.

Materials costs: According to the market price.

Logistics costs: Highway transport costs and ship transport.

Processing costs: Water, plant transport, argon, oxygen, carbon dioxide, acetylene, machine maintenance costs, workshop building repair costs and electricity.

Other costs: Inventory costs are zero because all the warehouse or storage cost is outsourced to storage companies.

Turnover: 4.2 billion RMB yuan for 2010. Before the financial crisis, the turnover was 10 billion RMB yuan per year. In 2009, the turnover was approximately 5 billion RMB yuan.

Processing steps: Raw material cutting $\rightarrow$ small part welding or assembly (inside the workshops) $\rightarrow$ welding or assembly of middle-sized parts (partly inside the workshops, partly outside) $\rightarrow$ final assembly on the berth.

Cultural factors: Nantong city, Jiangsu province (Eastern and coastal areas).

Workers 'training: Security assessment and skill assessment; $50 \%$ of the welders in the factory have welder certification.

Inspection methods: Incoming material inspection, prewelding inspection, welding process inspection, nondestructive test, and final inspection by the ship register.

Machine maintenance: Everyday machine cleaning and weekly machine maintenance by the specialized personal.

Material storage: Steel board and welding wire storage in a special warehouse.

Worker protection: All protective equipment such as masks or earplugs should be used.

\subsection{Company $F$}

This is a producer of marine diesel engines, located in Shandong province, in the eastern and coastal areas [9]. 


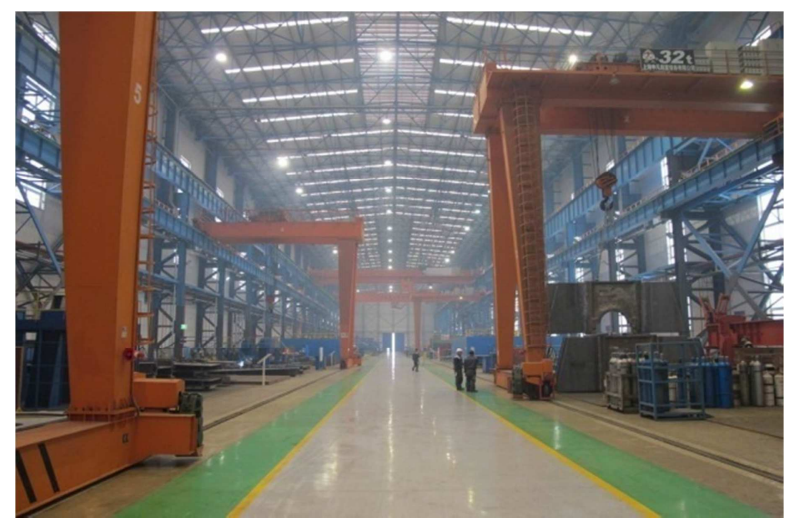

Fig. 6. Working environment of Company F (photo by author).

Number of workers: 123 welders. The welder performance qualification is based on EN 287 for welding workers and EN 1418 for welding operators.

Workers' qualifications: Qualified by DNV (Det Norske Veritas), GL (Germanischer Lloyd), BV (Bureau Veritas), or ABS (American Bureau of Shipping). Only Chinese welding certification is not accepted for work in company $\mathrm{F}$.

Plants: One welding workshop, one machining workshop, and one assembly workshop.

Manufacturing tools: Submerged arc welding, MAG (CO2 as shielded active gas) welding, MMA welding, MIG (argon as shielded inert gas) welding, stud welding, and TIG welding.

Materials: S235 steel board.

Environment: Well-constructed workshops with constant temperature and humidity conditions, and dust exhaust machines.

Workers' salary: 3000 RMB yuan per month. Overtime pay on workdays is 1.5 times the usual pay and on holidays and weekends 2 times the usual.

Materials costs: According to the market price in China.

Logistics costs: Specific logistics company to manage transportation matters.

Processing costs: The cost of welding seams is carefully calculated and divided into processing costs, consumption costs, NDT costs, and post-treatment cost. The processing costs in company $\mathrm{F}$ include shield gas costs $(\mathrm{CO} 2$, or $82 \%$ argon $+12 \% \mathrm{CO} 2)$, propane, welding wire, welding rod, welding flux, water and electricity. The total processing costs are $20 \%$ of the total costs.

Other costs: UT test: 50 RMB yuan per hour, VT test: 30 RMB yuan per hour, and MT test: 40 RMB yuan per hour.

Turnover: 0.6 billion RMB yuan for the entire factory in 2010. The margin for the welding workshop is $20 \%$ to $30 \%$.

Processing steps: Pre-treatment of materials $\rightarrow$ material cutting $\rightarrow$ part assembly and welding $\rightarrow$ painting $\rightarrow$ machining $\rightarrow$ assembly for the whole product $\rightarrow$ testing $\rightarrow$ product delivery. The pWPS is based on EN 15609-1. The WPQR is according to ISO 15614-1. The WPS is according to EN 15609-1.

Cultural factors: Shandong province (eastern and coastal areas).

Worker training: There is a welding training school in the welding workshop. Its purpose is to introduce new workers to the daily welding routines, focusing especially on the welding methods used in the factory.

Inspection methods: UT, VT, or MT tests are conducted throughout the welding process. All of the testing activities follow the standards EN 473, EN 12062, EN 1714, EN 5711, EN 970, and EN 1290. Each welding cell is inspected by more than one inspection staff member in order to ensure the welding seam quality.

Machine maintenance: Maintenance and calibration follow the standards EN ISO 9001/9002, EN ISO 3834-2, EN ISO 17662, DVS techn. Bulletin 3009, and DVS techn. Bulletin 0714. $[10,11]$

Material storage and treatment: The material storage and treatment rules cover every welding material. The handling and storage of covered welding electrodes, solid and cored welding wire, and welding flux have a significant influence on the weld quality.

Worker protection: Overalls, special masks, welding glasses, and welder gloves.

\section{Summary of Chinese Welding Industries}

The advantages of North China areas are: 1) two large harbors, Tianjin and Dalian, for easy export, 2) the worker qualifications in this area are easy to ensure, 3) the factories near Beijing have a higher business management level, 4) the workers' wage and material costs are at the medium level, 5) the workers in North China are known for their loyalty, 6) the North China does not have a humid season. The disadvantages of North China areas are: 1) the total welding management (TWM) is not completely implemented, 2) the ND test is inadequate in the production process, 3) the pWPS, WPQR, and WPS are usually overlooked, 4) the winter in North China is cold which will influence the welding quality if no sufficient heating works.

The advantages of eastern and coastal areas in China are: 1) many large harbors, such as Qingdao, Shanghai, Lianyungang and Ningbo, for easy export, 2) the highest level of business management, 3) worker qualifications in this area are easy to ensure, 4) a good history of cooperation with foreign companies, 5) the workers are known for their diligence, 6) the eastern and coastal Chinese areas do not have a cold winter, 7) the level of quality control and inspection is high. The disadvantages of eastern and coastal areas in China are: 1) workers' wages are the highest, 2) the eastern and coastal areas have a heavily humid season.

\section{The Finnish-Chinese Cooperation Situation and Improvement Suggestions}

Quality control and production management are two significant problems in Chinese small-scale welding 
factories, some medium-sized welding factories, and even some of the large and state-owned factories. To solve the two problems, advanced and standard production management theory, a suitable enterprise management system, and more welding production standards should be employed. Overall welding quality management, the Plan-Do-Check-Act (PDCA) cycle, the 5S methodology, the Six Sigma business management strategy, and more formal welding standards can help the factories to avoid management or quality problems efficiently $[13,14]$.

Cooperation with foreign companies can improve the enterprise management model, improve the reputation of the enterprise, enhance its credit, and increase its profitability. In the future, strengthening the cooperation between Chinese factories and Finnish or European companies will be an important issue that the Chinese factories should consider.

Suggestions for Finnish companies are: a) expanding their market in China, b) promoting their enterprise management system in China, and c) establishing a welding factory certification system in China. The implementation of these suggestions will reduce the obstacles of Finnish companies which aspire to find a Chinese subcontractor. Moreover, Chinese welding factories will feel more at ease in signing a contract with a Finnish contractor.

\section{Conclusion}

The production scale and conditions decide whether a factory can receive a foreign contract or not. The study shows that welding factories located in North China and eastern and coastal areas of China are more competitive than those in other areas. Large-scale or state-owned factories currently have enough domestic and foreign contracts, resulting in a lack of aspiration towards cooperation with new foreign companies. Choosing small and medium-sized Chinese factories as partners in cooperation is the suitable choice for Finnish or European companies today.

\section{References}

[1] Report book of the 14th Beijing Essen Welding \& Cutting Fair, p. 3.
[2] Report book of the 15th Beijing Essen Welding \& Cutting fair, p. 3 .

[3] Juha Vierros, Procurement Director of Global Sourcing, interviewed on 10 February 2011, Company company J.

[4] Yanshi Bi, Vice Factory Rector, interviewed on 10 March 2011, Company A., Beijing, China.

[5] Wang, Factory Rector, interviewed on 19 April 2011, Company B, Shijiazhuang, China.

[6] Yanfeng Zhang, Deputy Chief Engineer, interviewed on 6 May 2011, Company C, Qian'an, China.

[7] Zhao, General Manager, interviewed on 17 March 2011, Company D, Xuzhou, China.

[8] Zhang, Chief Welding Engineer, interviewed on 24 March 2011, Company E, Ningbo, China.

[9] Frank Wang, Welding Production Manager, interviewed on 10 May 2011, Company F, Qingdao, China.

[10] SFS-EN ISO 3834-1: en. 2006. Quality requirements for fusion welding of metallic materials. Part 1: criteria for the selection of the appropriate level of quality requirements. Brussels: European Committee for Standardization (CEN). 7 p.

[11] SFS-EN ISO 3834-2: en. 2006. Quality requirements for fusion welding of metallic materials. Part 2: comprehensive quality requirements. Brussels: European Committee for Standardization (CEN). $10 \mathrm{p}$.

[12] Xiaochen Yang, Paul Kah, Jukka Martikainen. Development of a Welding Product Quality Control and Management System Model for China. Mechanika-2015 conference, Kaunas, 2015.

[13] Xiaotong Yang, Jianjie Cui, Yongqi Zhang, Application Status and Improved Method of 5S Management in Pipeline Construction, Journal of Designation and Construction, Vol 33, No. 5, May 2014.

[14] Luciane de Oliveira Cunha, João Murta Alves, Application of Lean Manufacturing and Quality Management in Aeronautical Industry, International Review of Mechanical Engineering, Vol 8, No. 3, 2014.

[15] Jenni Toivinen, Paul Kah, Jukka Martikainen, Quality Requirements and Conformity of Welded Products in the Manufacturing Chain in Welding Network, International Journal of Mechanical Engineering and Applications, Vol 3, Issue 6, 2015. 